\title{
MODIFIKASI ALAT PEMOTONG NATA DE COCO SEMI OTOMATIS
}

\author{
Sulharman \\ ABSTRACT
}

\begin{abstract}
Modification was clipper of nata de coco with system work appliance owning knife block of athwart and lengthwise direction by using conveyor as conductor of nata de coco.

Clipper modification of nata de coco consist of 3(three) part of : knife block as part of functioning cut nata (knife block consist of 2 part of that is part of athwart and lengthwise), conveyor as conductor of nata de coco step into knife block, and workbench as part of uniting knife block and of conveyor. From result of test of performance appliance got crosscut ability 182 $\mathrm{kg} / \mathrm{hour}$.Difference of appliance capacities before and after modified equal to 1,4 times or there is $45,6 \%$. Energy at this appliance equal to 1300 watt. Tecno economic to the effort nata de coco by using this clipper is value of BEP Rp. $160.310 .850,7$, percentage of BEP $35,28 \%$,capacities $246,63 \mathrm{~kg}$ with time return capital 2,5 year.
\end{abstract}

Key words : clipper, nata de coco, modification, conveyor

\section{PENDAHULUAN}

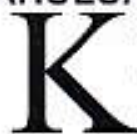

alimantan Timur merupakan penghasil kelapa yang cukup potensial, dapat tumbuh dengan baik. Hingga akhir tahun 2006 (Disbun Prop. Kaltim 2006), luas areal kelapa di Kalimantan Timur mencapai $47.807,50 \mathrm{Ha}$ dengan jumlah produksi $44.697,50$ ton. Buah kelapa ( Cocos nucifera) airnya dapat dimanfaatkan sebagai nata de coco. Produk nata de coco banyak di usahakan di Samarinda dan sekitarnya dalam skala home industri. Para pengusaha dalam proses pemotongan nata de coco masih menggunakan pemotongan manual, dan jarang yang menggunakan mesin potong. Pada alat pemotong nata de coco yang umum ada, terdiri dari pisau potong dari satu sisi saja, sehingga nata yang terpotong hanya membujur saja. Apabila kita menginginkan potongan nata berbentuk segi empat, maka potongan nata yang membujur tersubut kita masukkan lagi secara manual secara melintang, sehingga menghasilkan potongan segi empat. Penelitian ini bertujuan untuk memodifikasi alat pemotong nata de coco yang ada menjadi alat pemotong nata de coco secara semi otomatis sehingga kerja operator lebih efisien dan meningkatkan kapasitas produksi. Dengan adanya alat pemotong nata de coco ini diharapkan dapat meningkatkan jumlah produksi.

\section{BAHAN DAN METODE}

Bahan yang dibutuhkan untuk penelitian ini adalah : Nata de coco, dan bahan pembuatan 1 unit alat pemotong nata de coco. Adapun peralatan yang dibutuhkan adalah: Tachometer, stopwatch, baskom plastik, timbangan kapasitas $10 \mathrm{~kg}$, dan pengemas.

\section{Desain dan cara kerja alat}

Pada alat pemotong nata de coco yang ada, terdiri dari pisau potong (blok pisau) dari satu sisi saja, sehingga nata yang terpotong hanya membujur saja. Apabila kita menginginkan potongan nata berbentuk segi empat, maka potongan nata yang membujur tersubut kita masukkan lagi secara manual secara melintang, sehingga menghasilkan potongan segi empat ( seperti tampak pada Gambar 1). 


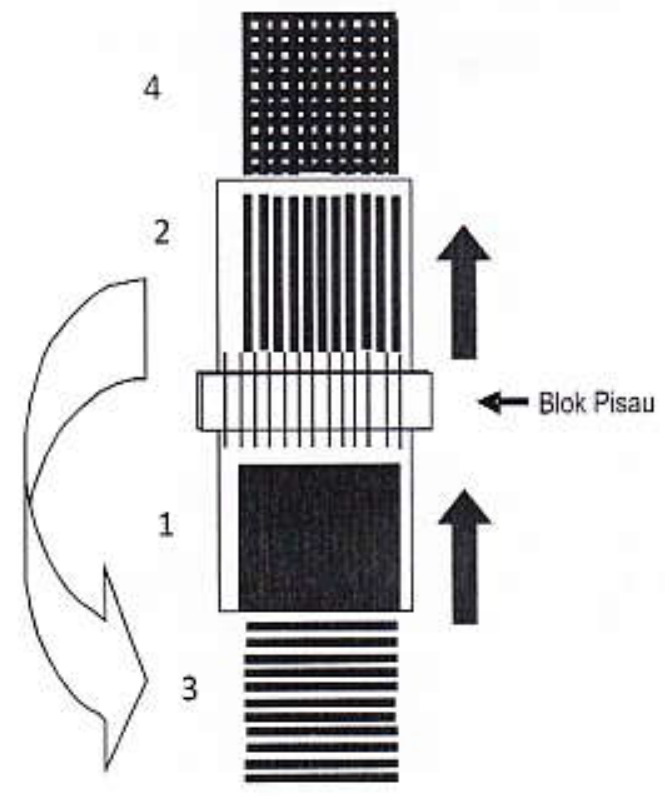

Gambar 1. Arah pemotongan alat pemotong nata de coco yang belum dimodifikasi ( tampak atas )

Pada tahap 1 nata yang belum terpotong memasuki pisau potong, tahap 2 nata terpotong arah membujur. Dari potongan membujur ini, nata dimasukkan lagi secara manual oleh operator (tahap 3) dengan arah melintang, sehingga didapatkan potongan nata segi empat (tahap 4).

Adapun desain alat pemotong nata de coco yang akan dimodifikasi (seperti tampak pada Gambar 2). Pada tahap 1 nata yang belum terpotong memasuki pisau potong, tahap 2 yaitu nata terpotong arah membujur. Dari potongan membujur ini, nata dimasukkan lagi secara otomatis (tahap 3) dengan arah melintang, sehingga didapatkan potongan nata segi empat (tahap 4).

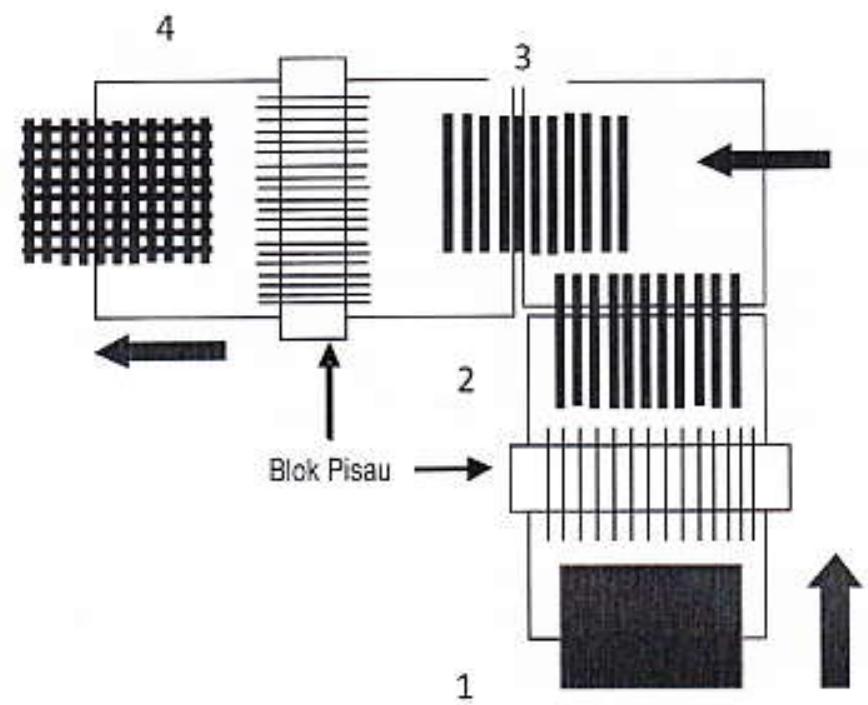

Gambar 2. Arah pemotongan alat pemotong nata de coco yang dimodifikasi ( tampak atas ) 


\section{Pengujian Pendahuluan}

Alat yang telah dibuat, diuji dengan meletakkan nata de coco yang belum terpotong pada alas yang terbuat dari teflon kemudian memasukkannya ke alat pemotong. Dari pengujian pendahuluan dapat diketahui kedalaman pemotongan (apakah terpotong) dan apakah konveyor kecepatannya tidak menyebabkan nata lari dari posisinya ( lurus ) terutama pada posisi belokan.

Pengujian

Apabila masalah pada pengujian pendahuluan sudah diatasi, maka dilakukan pengujian unjuk kerja alat yaitu dengan menimbang nata de coco yang belum terpotong kemudian memasukkannya ke alat pemotong. Catat waktu dan kapasitas pemotongan. Timbang kembali nata de coco yang telah terpotong, sehingga didapatkan kapasitas alat. Gambar 3. memperlihatkan diagram alir pengujian unjuk kerja alat pemotong nata de coco.

Tahapan proses pengujian sebagai berikut ;

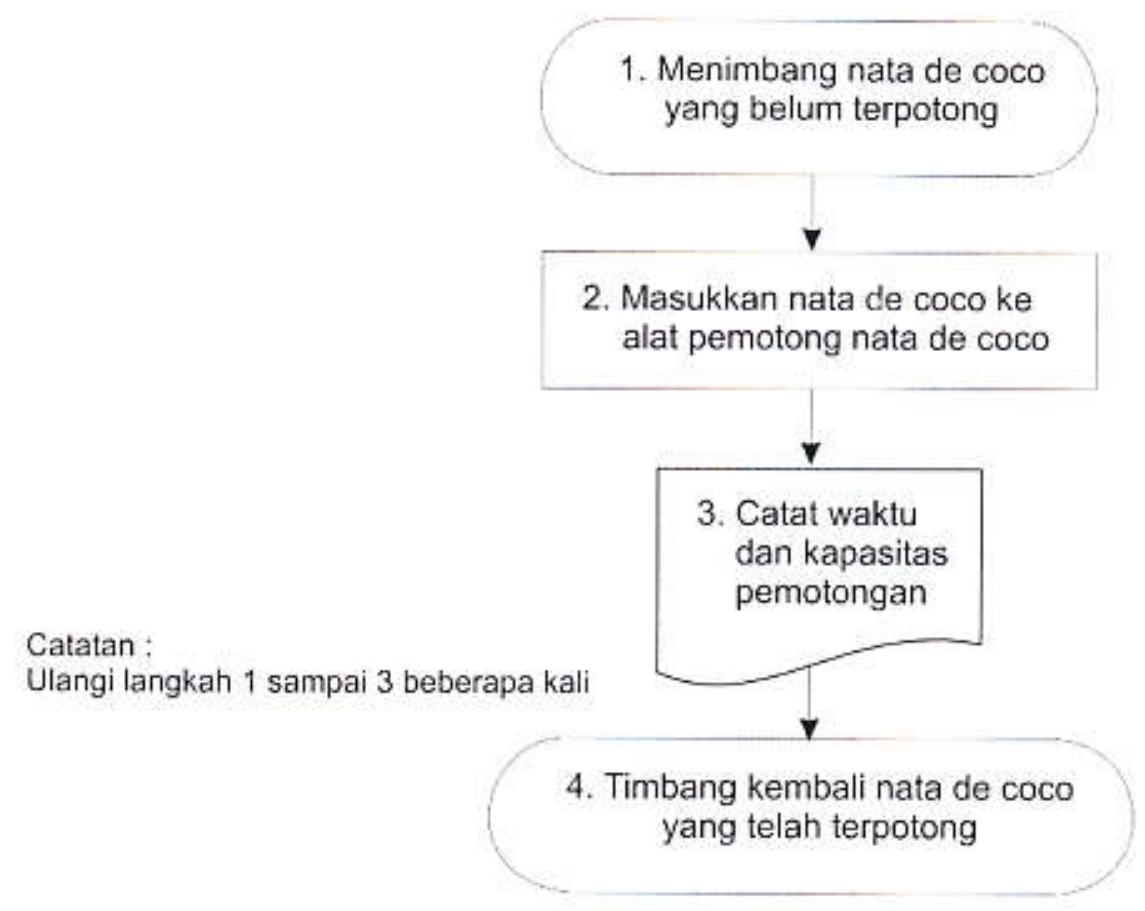

Gambar 3. Proses pengujian alat nata de coco yang telah dimodifikasi

\section{RANCANGAN ALAT PEMOTONG NATA DE COCO \\ Pendekatan Rancangan}

Alat pemotong nata de coco terdiri dari dua komponen utama yaitu blok pisau dan konveyor. Blok pisau terdiri dari dua bagian, yaitu satu diletakkan dari arah membujur sedangkan lainnya diletakkan pada arah melintang. Konveyor berada pada sisi bawah masing-masing blok pisau. Blok pisau dan konveyor tersebut dirangkai pada suatu meja kerja.

Prinsip kerja alat pemotong adalah nata kita letakkan pada alas (talenan) yang terbuat dari teflon lalu diletakkan di atas konveyor yang berputar. Nata tersebut masuk ke blok pisau, sehingga keluar dari blok pisau menjadi terpotong secara membujur. Kemudian nata yang telah terpotong secara membujur tersebut akan berjalan memasuki blok pisau yang posisinya melintang, sehingga nata akan terpotong secara persegi empat kecil dengan ukuran panjang dan lebar masing-masing 1 (satu) $\mathrm{cm}$.

\section{Rancangan Fungsional}

Konveyor

Konveyor berfungsi untuk menghantarkan nata yang diletakkan di atas talenan (alas) 
Sehingga dapat berjalan sendiri memasuki blok pisau tanpa bantuan operator. Konveyor terdiri dari 2 (dua) bagian. Yang pertama konveyor dengan ban karet, ini berfungsi untuk

menghantarkan talenan (alas ) yang di atasnya terdapat nata ke blok pisau, baik blok pisau yang arah membujur maupun melintang. Sedangkan konveyor ke dua merupakan konveyor yang berfungsi sebagai pembelok arah talenan, yang terdiri dari konveyor rol besi.

\section{Blok Pisau}

Blok pisau berfungsi sebagai alat untuk memotong nata. Blok pisau terdiri dari beberapa pisau yang berada pada rol. Jarak antar pisau dipisahkan oleh spacer (pemisah) sesuai dengan lebar nata yang akan kita potong.

\section{Meja Kerja}

Meja kerja berfungsi untuk merangkai antara konveyor dan blok pisau sehingga menjadi satu kesatuan yang saling menunjang kinerja alat.

\section{Rancangan Struktural}

Jenis konveyor yang digunakan dalam rancangan ini adalah belt konveyor. Dengan panjang $121 \mathrm{~cm}$ dan lebar $50 \mathrm{~cm}$ untuk masing masing bagian. Untuk roller konveyor berukuran diameter $8 \mathrm{~cm}$ dan panjang $50 \mathrm{~cm}$ sebanyak 3 buah. Roller konveyor digerakkan oleh motor penggerak $1 / 4 \mathrm{Hp}$.

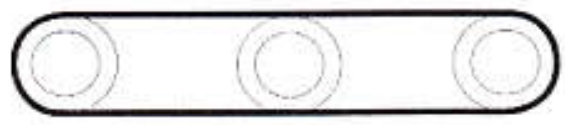

Gambar 4. Konveyor dan roller konveyor

Blok pisau terbuat dari rol dengan diameter $6 \mathrm{~cm}$ dan panjang $50 \mathrm{~cm}$, pisau terbuat dari stainles dengan diameter dalam $6 \mathrm{~cm}$ dan diameter luar $8,5 \mathrm{~cm}$. Pisau dimasukkan pada rol dengan jumlah pisau sebanyak 12 buah. Blok pisau digerakkan oleh motor penggerak dengan daya $1 / 4 \mathrm{Hp}$ dengan perantaraan puli dan $v$ belt. Ukuran selengkapnya bisa dilihat pada Lampiran Gambar.
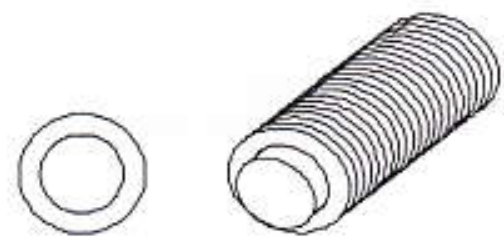

Gambar 5. Pisau dan blok pisau

Meja kerja terbuat dari besi siku $3 \times 3 \mathrm{~cm}$, tebal $3 \mathrm{~mm}$. Lebar meja $65 \mathrm{~cm}$ dan panjang meja $121 \mathrm{~cm}$ dengan tinggi $75 \mathrm{~cm}$ sebanyak 2 buah. Meja pembelok terbuat dari besi siku $3 \times 3 \mathrm{~cm}$, tebal $3 \mathrm{~mm}$, panjang $35 \mathrm{~cm}$, lebar $65 \mathrm{~cm}$, dan tinggi $75 \mathrm{~cm}$.
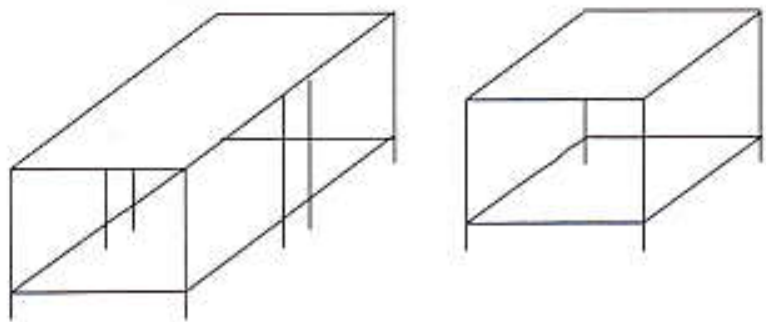

Gambar 6. Meja pemotong dan meja pembelok 


\section{HASIL DAN PEMBAHASAN}

\section{Pengujian Pendahuluan}

Pengujian pendahuluan ini bertujuan untuk mengetahui kerja alat secara keseluruhan, apakah alat dapat bekerja sesuai dengan tujuan penelitian (alat pemotong nata de coco secara semi otomatis sehingga kerja operator lebih efisien dan meningkatkan kapasitas produksi).

Dari hasil tes pendahuluan alat dapat bekerja sesuai dengan rencana namun masih diperlukan pengaturan alur pisau pada teplon karena masih ada nata yang belum terpotong karena posisi pisau tidak tepat di alur teplon.

\section{Pengujian}

Pengujian bertujuan untuk menguji unjuk kerja alat secara lebih akurat lagi dengan melakukan pengulangan uji. Pengujian dilakukan dengan menimbang nata de coco (lembaran) kemudian memasukkannya ke alat pemotong dan mencatat waktu mulai masuk sampai keluar dari alat pemotong. Pengujian dilakukan dengan 5 (lima) kali pengulangan. Hasil pengujian terlihat pada Tabel 1.

Tabel 1. Hasil Pengujian Kapasitas Alat Pemotong Nata De Coco

\begin{tabular}{|c|c|c|c|c|}
\hline $\begin{array}{c}\mathbf{n} \\
\text { (ulangan })\end{array}$ & $\begin{array}{c}\text { Input } \\
\text { ( } \mathbf{~ k g ~})\end{array}$ & $\begin{array}{c}\text { Output } \\
\text { ( kg })\end{array}$ & $\begin{array}{c}\mathbf{t} \\
\text { ( detik })\end{array}$ & $\begin{array}{c}\text { Kapasitas } \\
\text { ( kg/jam })\end{array}$ \\
\hline 1 & 1 & 1 & 24.91 & 144 \\
\hline 2 & 1 & 1 & 16.41 & 219 \\
\hline 3 & 1 & 1 & 19.17 & 187 \\
\hline 4 & 1 & 1 & 16.02 & 224 \\
\hline 5 & 1 & 1 & 26.38 & 136 \\
\hline Rata-rata & & & $\mathbf{2 0 . 5 7}$ & $\mathbf{1 8 2}$ \\
\hline
\end{tabular}

Dari Tabel 1 di atas didapat rata-rata kapasitas alat pemotong nata de coco adalah 182 $\mathrm{kg} / \mathrm{jam}$. Pada ulangan 1 dan 5 waktu 24,91 dan 26,38 detik disebabkan talenan nata sangkut pada sambungan konveyor sehingga menekan blok pisau. Konveyor pada daerah sambungan mudah sobek, sehingga perlu dicari bahan konveyor yang tidak mudah sobek bila disambung.

\begin{tabular}{|r|l|r|r|}
\hline No. & \multicolumn{1}{|c|}{ KELOMPOK BIAYA } & \multicolumn{2}{c|}{ Jumlah } \\
\hline & PERKIRAAN MODAL TETAP & & \\
\hline 1 & Tanah & $100,000,000$ & \\
\hline & Pembelian $200 \mathrm{~m}^{2}$ & & \\
\hline 2 & Bangunan & $250,000,000$ & \\
\hline & Bangunan/pabrik $175 \mathrm{~m}^{2}$ & $3,500,000$ & \\
\hline & Instalasi air dan listrik & & $\mathbf{3 5 3 , 5 0 0 , 0 0 0}$ \\
\hline & & & \\
\hline 3 & Mesin \& Peralatan & $29,000,000$ & \\
\hline & a. Alat Pemotong Nata & $10,500,000$ & \\
\hline & b. Kulkas ( 3 buah ) @ Rp.3.500.000 & $1,800,000$ & \\
\hline & c. Kompor Gas ( 4 buah ) @ Rp.450.000 & 600,000 & \\
\hline & d. Timbangan (2 buah ) @ Rp. 300.000 & $4,000,000$ & \\
\hline & e. Mesin Press (4 buah ) @Rp. 1000.000 & 600,000 & \\
\hline & f. Panci ( 4 buah ) @ Rp. 150.000 & 600,000 & \\
\hline & g. Baki 30 buah @ Rp. 20.000 & 900,000 & \\
\hline & h. Baskom 30 buah @ Rp. 30.000 & 80,000 & \\
\hline & i. Botol 40 buah @ Rp. 2000 & 300,000 & \\
\hline & k. Perlengkapan lainnya & & \\
\hline
\end{tabular}




\begin{tabular}{|c|c|c|c|}
\hline \multirow[t]{7}{*}{4} & Peralatan Kantor & $5,000,000$ & \\
\hline & Cadangan kenaikan dana & $2,000,000$ & \\
\hline & & & $55,380,000$ \\
\hline & JUMLAH MODAL TETAP & & $408,880,000$ \\
\hline & & & \\
\hline & PERKIRAAN MODAL KERJA & & \\
\hline & (3.BULAN) & & \\
\hline \multirow[t]{17}{*}{1} & Persediaan & & \\
\hline & a. Bahan baku ( air kelapa) 5.824 ltr per & & \\
\hline & bulan & $4,368,000$ & \\
\hline & Rp. 5000 per $20 \operatorname{ltr}(5.824 / 20 \times 5.000$ & & \\
\hline & $\times 3$ bulan ) & & \\
\hline & b. Gula pasir $5,8 \mathrm{~kg}$ per bulan & & \\
\hline & @ Rp. $10.000 / \mathrm{kg}$ & 174,000 & \\
\hline & c. Elpiji, 16 tabung/ bulan Rp. 60.000 /tabung & $2,880,000$ & \\
\hline & d. Pupuk ZA $(1,16 \mathrm{~kg}$ per bulan $\times$ Rp. $5000 / \mathrm{kg}$ & 17,400 & \\
\hline & $\times 3$ bulan ) & & \\
\hline & e. Plastik kemasan 5.824 bungkus / bulan & $6,988,800$ & \\
\hline & Rp. 400 per kemasan & & \\
\hline & f. Bahan penolong lainnya & 100,000 & \\
\hline & g. Listrik & 900,000 & \\
\hline & h. Air & 300,000 & \\
\hline & i. Transport (Rp.200.000/bulan) & 600,000 & \\
\hline & & & $16,328,200$ \\
\hline \multirow[t]{8}{*}{2} & Tenaga Kerja & & \\
\hline & a. Gaji pimpinan dan administrasi 1 orang & $4,500,000$ & \\
\hline & 1 orang@1.500.000 & & \\
\hline & c. Tenaga kerja produksi 3 orang @ 700.000 & $6,300,000$ & \\
\hline & d. Tenaga pemasaran 1 orang @ 800.000 & $2,400,000$ & \\
\hline & & & $13,200,000$ \\
\hline & JUMLAH MODAL KERJA & & $29,528,200$ \\
\hline & KEBUTUHAN INVESTASI AWAL & & $438,408,200$ \\
\hline
\end{tabular}

-) Sebulan 20 hari kerja

Tabel Perhitungan biaya Produksi selama1 tahun

\begin{tabular}{|r|l|r|l|}
\hline No. & \multicolumn{1}{|c|}{ KELOMPOK BIAYA } & \multicolumn{2}{c|}{ Jumlah } \\
\hline & BIAYA TETAP & & \\
\hline 1 & Gaji (Rp.2.300.000 $\times 12$ ) & $27,600,000$ & \\
\hline 2 & Biaya Pemeliharaan & & \\
\hline & a. Mesin (3\%) & $1,481,400$ & \\
\hline & b. Bangunan (3\%) & $7,500,000$ & \\
\hline 3 & Penyusutan & $4,938,000$ & \\
\hline & a. Mesin (10\%) & $25,000,000$ & \\
\hline & b. Bangunan (10\%) & & \\
\hline 4 & Bunga Modal & $54,345,600$ & \\
\hline & a. Modal tetap (12\%) & $4,744,230$ & \\
\hline & b. Modal Kerja (15\%) & \\
\hline
\end{tabular}




\begin{tabular}{|c|l|r|r|}
\hline 5 & Biaya Umum 10\% biaya gaji & $2,760,000$ & \\
\hline & JUMLAH & & $128,369,230$ \\
\hline & BIAYA TIDAK TETAP & & \\
\hline 1 & Upah tenaga kerja & $25,200,000$ & \\
\hline 2 & Bahan baku ( air kelapa) & $17,472,000$ & \\
\hline 3 & Gula pasir & 696,000 & \\
\hline 4 & Elpiji & $11,520,000$ & \\
\hline 5 & Pupuk ZA & 69,600 & \\
\hline 6 & Plastik kemas & $27,955,200$ & \\
\hline 7 & Bahan penolong lainnya & 400,000 & \\
\hline 8 & Listrik & $3,600,000$ & \\
\hline 9 & Air & $1,200,000$ & \\
\hline 10 & Biaya Transport & $2,400,000$ & \\
\hline & JUMLAH & & $\mathbf{9 0 , 5 1 2 , 8 0 0}$ \\
\hline & BIAYA PRODUKSI 1 TAHUN & $\mathbf{2 1 8 , 8 8 2 , 0 3 0}$ \\
\hline
\end{tabular}

A. Perhitungan Laba Rugi (dalam 1 tahun )

Hasil penjualan $5.824 \mathrm{~kg} \mathrm{x} 12 \times 6.500$

Rp. 454.272.000,-

Biaya produksi

Keuntungan kotor

Pajak (metode progresif)

Keuntungan bersih per tahun

Rp. 218.882.030.-

Rp. 235.389.970,-

Rp. $67.386,489,50$

Rp. $168.003 .480,50$

B. Perhitungan Batas Laba Rugi ( BEP)

1. Nilai BEP

$$
\begin{aligned}
& =1-\frac{\text { Biaya Tetap }}{\text { Biaya Tidak Tetap }} \\
& =1-\frac{\text { Rp. } 128 \cdot 369 \cdot 230}{\text { Rp. } 90 \cdot 512.800} \\
& \text { Rp. } 454 \cdot 272.000
\end{aligned}
$$

Rp. $1.603 .100 .850,7$

2. Persentase BEP

$$
\begin{aligned}
& =\frac{\text { Biaya Tetap }}{\text { Hasil Penjualan - Biaya Tidak Tetap }} \times 100 \% \\
& =\frac{\text { Rp. } 128.369 .230}{\text { Rp. } 454.272 .000-\text { Rp. } 90.512 .800} \times 100 \% \\
& =35,28 \%
\end{aligned}
$$


3. Kapasitas

$$
\begin{aligned}
& =35,28 \% \times 69,888 \mathrm{~kg} \\
& =\frac{24.663,2}{100} \\
& =246,64 \mathrm{~kg}
\end{aligned}
$$

4. Perhitungan Balik Modal

$$
\begin{aligned}
& =\frac{\text { Keuntungan bersih per tahun } \times \text { penyusutan (mesin) }}{\text { Investasi Awal }} \times 100 \% \\
& =\frac{\text { Rp. } 168.003 .480,50 \times \text { Rp. } 4.938 .000}{\text { Rp. } 438.408 .200} \times 100 \% \\
& =0,3944 \%
\end{aligned}
$$

Waktu Balik Modal

$$
\begin{aligned}
& =\frac{1}{0,3944} \\
& =2,5 \text { tahun }
\end{aligned}
$$

\section{KESIMPULAN DAN SARAN \\ Kesimpulan}

Kapasitas potong nata de coco yang dapat dihasilkan oleh alat modifikasi ini 182 $\mathrm{kg} / \mathrm{jam}$. Perbedaan kapasitas alat sebelum dan sesudah dimodifikasi sebesar 1,4 kali ( 1456 $\mathrm{kg} / 1000 \mathrm{~kg}$ ) atau ada kenaikkan $45,6 \%$ ( $1456 \mathrm{~kg} 1000 \mathrm{~kg} / 1000 \mathrm{~kg} \times 100 \%$ ) sedangkan daya listrik yang dibutuhkan untuk menggerakkan alat ini 1300 watt. Tekno ekonomi untuk usaha nata de Coco dengan menggunakan alat pemotong ini adalah Nilai BEP Rp. $160.310 .850,7$, persentase
BEP $35,28 \%$, kapasitas $246,63 \mathrm{~kg}$ dengan waktu balik modal 2,5 tahun. Konveyor pada daerah sambungan mudah sobek, sehingga perlu dicari bahan konveyor yang tidak mudah sobek bila disambung.

\section{DAFTAR PUSTAKA}

Anonim, 1999. Nata De Coco. PDII LIPI. Jakarta

Gupta dan Khurmi.1984.A Text Book of Machine Design. Eurasia Publishing House.New Delhi Hutahaean Ramses. 2005. Mekanisme dan Dinamika Mesin. Andi. Yogyakarta

Sularso, 2004. Dasar Perencanaan Dan Pemilihan Elemen Mesin. Pradnya Paramita. Jakarta Sutedja Wiraatmadja, 2002. Pengiris Dan Pemotong. Penebar Swadaya. Jakarta Tosin Rijanto. 1994. Flow Chart untuk Siswa dan Mahasiswa. Dinastindo. Jakarta Zainuri Muhib, 2006. Mesin Pemindah Bahan. Andi Yogyakarta. Yogyakarta 